\title{
Manejo de capim pé-de-galinha em lavouras de soja transgênica resistente ao glifosato
}

\author{
André da Rosa Ulguim(1), Leandro Vargas(2), Dirceu Agostinetto(1), Taísa Dal Magro(3), \\ Nixon da Rosa Westendorff(') e Marcelo Timm Holz ${ }^{(1)}$
}

\begin{abstract}
(1)Universidade Federal de Pelotas, Faculdade de Agronomia Eliseu Maciel, Departamento de Fitossanidade, Centro de Herbologia, Campus Universitário, Caixa Postal 354, CEP 96010-900 Pelotas, RS. E-mail: andre_ulguim@yahoo.com.br, dirceu.agostinetto@pq.cnpq.br, nwestendorff@gmail.com, marcelotimm@yahoo.com.br (2)Embrapa Trigo, BR 285, Km 174, Caixa Postal 451, CEP 99001-970 Passo Fundo, RS. E-mail: leandro.vargas@embrapa.br (3)Universidade de Caxias do Sul, Campus Vacaria, Avenida Presidente Kennedy, no 2.020, CEP 95200-000 Vacaria, RS. E-mail: taisadm@yahoo.com.br
\end{abstract}

Resumo - O objetivo deste trabalho foi avaliar a resistência de capim pé-de-galinha (Eleusine indica) ao glifosato, em lavouras de soja transgênica; avaliar o efeito de aplicações de glifosato em diferentes estádios de desenvolvimento; identificar práticas agronômicas associadas à seleção de biótipos resistentes; e avaliar a eficiência dos herbicidas cletodim, fluazifope-P-butílico, clomazona, glufosinato de amônio e glifosato nas plantas resistentes. Plantas escapes ao tratamento com glifosato foram coletadas em 24 propriedades, no Rio Grande do Sul. As plantas foram cultivadas em casa de vegetação, tendo-se avaliado a sua resistência ao glifosato. Os acessos resistentes foram selecionados e avaliados quanto ao efeito da aplicação do glifosato em diferentes estádios de crescimento e quanto à sensibilidade aos herbicidas. Foi aplicado um questionário aos produtores para identificação das práticas agronômicas associadas às falhas no controle. O controle de E. indica pelo glifosato é mais efetivo com a aplicação em estádios iniciais de desenvolvimento. Práticas agronômicas, como uso contínuo de baixas doses do herbicida, aplicação em estádios de desenvolvimento avançados das plantas daninhas (mais de um afilho) e a ausência de rotação de culturas foram relacionadas às falhas de controle observadas. Os herbicidas cletodim, fluazifope-P-butílico e glufosinato de amônio são alternativas eficientes para o controle de E. indica.

Termos para indexação: Eleusine indica, Glycine max, dosagem, eficiência de controle, estádio fenológico, resistência ao glifosato, roundup ready.

\section{Management of goose grass on transgenic soybean, resistant to glyphosate}

Abstract - The objective of this work was to evaluate the resistance of goose grass (Eleusine indica) to glyphosate application in transgenic soybean crops; evaluate the effect of glyphosate applications in different growth stages; identify the main agronomic practices associated with the selection of resistant biotypes; and evaluate the effect of the herbicides clethodim, fluazifop-p-butyl, clomazone, glufosinate ammonium, and glyphosate on resistant plants. Plants that survived glyphosate application were collected on 24 properties in the state of Rio Grande do Sul, Brazil. Plants were grown in greenhouse and their resistance to glyphosate was evaluated. The resistant accessions were selected and evaluated as to the effect of glyphosate application on different growth stages and to their sensitivity to the herbicides. A questionnaire was given to producers in order to identify agronomic practices associated with control failures. The control of $E$. indica by glyphosate is more effective at initial growth stages. Agronomic practices, such as continued use of low doses of glyphosate, application on advanced weed growth stages (more than one tiller), and absence of crop rotation were related to the observed control failures. The herbicides clethodim, fluazifop-p-butyl, and glufosinate ammonium are efficient alternatives to control E. indica.

Index terms: Eleusine indica, Glycine max, dosage, control efficiency, phenological stage, resistance to glyphosate, roundup ready.

\section{Introdução}

A resistência das plantas a herbicidas é definida como a capacidade inerente e herdável de um biótipo de sobreviver e se reproduzir após exposição à dose de registro para controle da espécie, obedecidos os critérios de aplicação, como estádio vegetativo indicado e condições de clima (Gazziero et al., 2009).

No Estado do Rio Grande do Sul, as espécies Euphorbia heterophylla L., Ipomoea spp., Conyza spp., 
Richardia brasiliensis Gomes e Eleusine indica (L.) Gaertn são consideradas como as de maior dificuldade de controle por glifosato, por produtores de soja Roundup Ready. Destas, apenas Conyza spp. apresenta registro de resistência ao herbicida, e E. heterophylla tem resistência de baixo nível (Vargas et al., 2011). Contudo, também há relatos, por parte de produtores e técnicos, da ocorrência de falhas de controle do capim pé-de-galinha ( $E$. indica) pelo glifosato, em lavouras de soja RR (Nohatto, 2010). Portanto, é provável que esta planta daninha tenha adquirido resistência ao herbicida glifosato.

O capim pé-de-galinha é uma espécie autógama, com ciclo fotossintético do tipo $\mathrm{C} 4$ e reprodução via sementes (Kissmann, 2007). A hipótese de resistência da espécie ao glifosato é reforçada pelo fato de que, atualmente, o controle de plantas daninhas na soja RR tem sido feito por meio de duas a três aplicações de glifosato, por ciclo da cultura (Vargas et al., 2007). $\mathrm{O}$ uso repetido do herbicida caracteriza uma situação de alta pressão de seleção, o que pode favorecer o desenvolvimento de biótipos resistentes preexistentes na população (Christoffoleti \& López-Ovejero, 2003; Vila-Aiub et al., 2008).

Os fatores que mais influenciam a seleção de biótipos de plantas daninhas resistentes a herbicidas são: intensidade de uso, eficiência do herbicida e sua persistência no ambiente; especificidade do mecanismo de ação; e baixa eficiência de métodos de controle alternativos, em comparação aos métodos químicos (Roman et al., 2004; Zelaya et al., 2004). Assim, práticas agronômicas, como rotação do mecanismo de ação do herbicida, rotação de culturas e associação de métodos de controle, devem ser adotadas para mitigar a evolução da ocorrência de casos de resistência. Entretanto, no Rio Grande do Sul, menos da metade dos produtores de soja realizam a rotação de culturas (Nohatto, 2010).

A simples ocorrência de falhas de controle de determinada espécie não caracteriza resistência, pois esta pode ser causada por outros fatores. Em geral, plantas jovens são mais sensíveis a herbicidas e mais facilmente controladas do que plantas em estádios mais avançados de desenvolvimento (Silva et al., 2007). Desse modo, deve-se priorizar a aplicação do herbicida na época adequada, para proporcionar melhor eficiência de controle.

Medidas complementares de manejo com herbicida devem ser adotadas para reduzir a pressão de seleção.
Neste sentido, a associação e a utilização de herbicidas com mecanismos de ação diferentes são preconizadas no manejo de plantas daninhas resistentes ao glifosato (Shaner, 2000; Johnson \& Gibson, 2006).

O objetivo deste trabalho foi avaliar a resistência de capim pé-de-galinha ao glifosato, em lavouras de soja transgênica; avaliar o efeito de aplicações de glifosato em diferentes estádios de desenvolvimento; identificar práticas agronômicas associadas à seleção de biótipos resistentes; e avaliar a eficiência dos herbicidas cletodim, fluazifope-P-butílico, clomazona, glufosinato de amônio e glifosato nas plantas resistentes.

\section{Material e Métodos}

Vinte e quatro propriedades rurais produtoras de soja transgênica RR foram visitadas, em oito municípios Rio Grande do Sul, no ano agrícola de 2008/2009. Os municípios escolhidos foram os de maior produção de soja no estado (Instituto Brasileiro de Geografia e Estatística, 2008): Boa Vista do Incra, Carazinho, Cruz Alta, Ijuí, Lagoa Vermelha, Passo Fundo, Santa Bárbara do Sul e Tupanciretã. Plantas de 39 biótipos de capim pé-de-galinha, escapes ao controle do herbicida glifosato, foram coletadas e acondicionadas, individualmente, para a retirada das sementes em laboratório. Cada ponto de coleta foi georeferenciado e, em cada local, aplicou-se questionário ao proprietário para estabelecer relações entre falhas de controle de capim pé-de-galinha pelo glifosato e práticas agronômicas utilizadas pelos produtores.

Os biótipos coletados nas propriedades foram avaliados em casa de vegetação, com ensaio em vasos para identificar os resistentes ao glifosato. Quando as plantas encontravam-se no estádio de quatro folhas a um afilho, o herbicida glifosato foi aplicado na dose de $2.160 \mathrm{~g} \mathrm{ha}^{-1}$ do e.a. (equivalente ácido), correspondente à dose máxima registrada para esse herbicida na cultura da soja (Brasil, 2010). Para a aplicação, foi utilizado pulverizador costal, pressurizado a $\mathrm{CO}_{2}$, com pontas do tipo leque 110.015 , que proporcionaram volume de aplicação de $150 \mathrm{~L} \mathrm{ha}^{-1}$. O controle das plantas foi avaliado visualmente aos 28 dias após a aplicação do tratamento (DAT). Dois biótipos (12.1 e 12.3) com menor sensibilidade inicial ao glifosato, oriundos do Município de Boa Vista do Incra, foram selecionados para realização dos experimentos posteriores.

$\mathrm{O}$ experimento, para avaliação da eficiência do glifosato quando aplicado em diferentes estádios de 
crescimento do capim pé-de-galinha foi realizado durante o período de outubro a dezembro de 2011, em casa de vegetação, em delineamento inteiramente casualizado, com quatro repetições. Foram semeadas três sementes por vaso dos biótipos previamente selecionados, e de um biótipo reconhecidamente suscetível, coletado em área sem histórico da aplicação de glifosato, no Município de Camaquã, RS. Após a emergência das plantas, realizou-se o desbaste para atingir população de duas plantas por vaso.

Os tratamentos foram dispostos em arranjo tri-fatorial, em que: o fator A testou os três biótipos de capim pé-de-galinha, o fator B constou de estádios de desenvolvimento das plantas (duas folhas, quatro folhas e um ou dois afilhos) e o fator $\mathrm{C}$ representou a aplicação ou não do herbicida glifosato na dose $1.080 \mathrm{~g} \mathrm{ha}^{-1}$ do e.a. A aplicação dos tratamentos foi realizada aos 22, 25 e 36 dias após a semeadura (DAS), momento em que as plantas de capim pé-de-galinha atingiram os estádios de duas folhas, quatro folhas e de um a dois afilhos, respectivamente. A aplicação foi realizada de modo similar ao descrito anteriormente.

As variáveis avaliadas foram: controle aos 10, 20 e 30 DAT, e massa de matéria seca da parte aérea, aos 30 DAT. A avaliação do controle foi feita com escala percentual, em que zero representou ausência de sintomas, sem a morte das plantas (Frans et al., 1986). Para a determinação da massa de matéria seca da parte aérea, realizou-se a coleta do material, com posterior secagem em estufa de circulação forçada de ar, a $60^{\circ} \mathrm{C}$, até massa constante.

Os dados foram analisados quanto à normalidade e à homocedasticidade, pelos testes de Shapiro-Wilk e Hartley, respectivamente, com posterior análise da variância, a 5\% de probabilidade. Para comparação das médias, utilizou-se o teste de Tukey, a 5\% de probabilidade, para os fatores biótipo e estádios de crescimento, e o teste $t$, também a $5 \%$ de probabilidade, para a aplicação ou não do glifosato.

O tempo de cultivo consecutivo de soja RR na área, os tipos de rotação e sucessão de culturas utilizados, a época da rotação, o número de aplicações e as doses utilizadas de glifosato durante o ciclo da soja foram obtidos por meio da aplicação de questionário aos produtores. Os dados foram expressos em percentual, tendo-se identificado a distribuição de casos de capim pé-de-galinha com suspeita de resistência ao glifosato.
Para avaliação dos herbicidas cletodim, fluazifote-P-butílico, clomazona, glufosinato de amônio e glifosato nos biótipos de capim pé-de-galinha selecionados, conduziu-se experimento em casa de vegetação, em vasos com capacidade de $0,5 \mathrm{~L}$, no período de outubro a dezembro de 2011. A semeadura foi realizada de forma semelhante à descrita anteriormente. Utilizou-se o delineamento experimental de blocos ao acaso, com quatro repetições, em arranjo fatorial, em que o fator A testou os biótipos 12.1, 12.3 e suscetível de capim pé-de-galinha; e o fator $\mathrm{B}$ avaliou os herbicidas cletodim (108 $\mathrm{g} \mathrm{ha}^{-1}$ do i.a.), fluazifope-P-butílico (187,5 $\mathrm{g} \mathrm{ha}^{-1}$ do i.a), clomazona (720 $\mathrm{g} \mathrm{ha}^{-1}$ do i.a), glufosinato de amônio (300 $\mathrm{g} \mathrm{ha}^{-1}$ do i.a) e glifosato (1.080 $\mathrm{g} \mathrm{ha}^{-1}$ do e.a). No tratamento com cletodim, foi adicionado à calda o adjuvante óleo mineral, na proporção de $0,5 \%$. Como no experimento anterior, a aplicação dos tratamentos foi feita aos 25 DAS, quando as plantas encontravam-se no estádio de quatro folhas a um afilho.

Avaliou-se o controle (\% de plantas mortas) aos 9,18 e 27 DAT. Os dados obtidos foram analisados quanto à normalidade e à homocedasticidade, pelos testes de Shapiro-Wilk e Hartley, respectivamente. A análise da variância foi realizada, a 5\% de probabilidade e as médias foram comparadas pelo teste de Tukey, a 5\% de probabilidade.

\section{Resultados e Discussão}

Os testes de normalidade e homocedasticidade indicaram não ser necessária a transformação dos dados obtidos. Verificou-se interação significativa entre os fatores estudados, para todas as variáveis analisadas, no experimento de avaliação de estádios de aplicação de glifosato. Quando as plantas de capim pé-de-galinha receberam a aplicação de glifosato no estádio de duas folhas, o controle foi satisfatório, próximo ou igual a $100 \%$, em todas as avaliações (Tabela 1). Já quando a aplicação foi realizada nos estádios de quatro folhas e de um ou dois afilhos, constatou-se que até o biótipo reconhecidamente suscetível apresentou redução de controle. Esses resultados são indicativos de que quanto mais avançado o estádio de desenvolvimento do capim pé-de-galinha, menor a sensibilidade ao glifosato. A aplicação de glifosato em estádio de dez folhas, em Conyza spp., resultou em controle $10 \%$ maior, em comparação à aplicação no pré-florescimento, e a 
diferença de controle observada foi atribuída ao estádio de desenvolvimento das plantas (Moreira et al., 2010).

$\mathrm{O}$ efeito da época de aplicação de herbicidas, em capim pé-de-galinha, também foi relatado em plantas tolerantes ao herbicida quincloraque (Zawierucha \& Penner, 2001). As plantas foram mais sensíveis ao quincloraque quando receberam a aplicação doherbicida em estádio de uma ou duas folhas, em comparação à aplicação no estádio de três ou quatro folhas, ou de um ou dois afilhos, o que confirma que a espécie apresenta capacidade diferencial de metabolização do herbicida de acordo com a fase de crescimento. Entretanto, casos de metabolismo diferencial ao glifosato, nesta espécie, não foram encontrados na literatura.

A massa de matéria seca da parte aérea do biótipo 12.3, aos 30 DAT, foi superior a do biótipo suscetível, após aplicação de glifosato no estádio de um ou dois afilhos. Não houve diferença entre os biótipos com a aplicação de glifosato nos demais estádios.

As falhas de controle de capim pé-de-galinha observadas não podem ser atribuídas somente à aplicação do glifosato em estádio avançado de crescimento das plantas, pois outros fatores podem estar envolvidos, como dose do herbicida e tecnologia de aplicação. A análise dos questionários aplicados aos produtores evidenciou que a maioria das áreas (77\%) é cultivada com soja há mais de cinco anos consecutivos (Figura 1). Este resultado pode ser relacionado às vantagens que a tecnologia da soja transgênica proporciona aos agricultores, como utilização do glifosato em pós-emergência da cultura, além da praticidade e da eficiência do produto no controle de plantas daninhas. Em estudo semelhante, constatou-se que mais de $80 \%$ dos produtores amostrados cultivam soja RR de forma consecutiva há mais de cinco anos na mesma área (Nohatto, 2010). Esta prática de manejo apresenta alto risco de seleção de biótipos de plantas daninhas resistentes, em razão do uso continuado de um mesmo herbicida, por vários anos, na mesma área.

Uma das principais práticas para evitar o surgimento de resistência, por meio da redução da pressão de seleção, é a rotação de mecanismos de ação dos herbicidas, o que é facilitado quando se realiza a rotação de culturas. Neste sentido, verificou-se que,

Tabela 1. Controle (\% de plantas mortas) e massa de matéria seca da parte aérea (g por planta) de biótipos (12.1, 12.3 e susceptível) de Eleusine indica oriundos de plantas escapes ao controle com glifosato, em resposta à aplicação do herbicida na dose de $1.080 \mathrm{~g} \mathrm{ha}^{-1}$ do e.a., em diferentes estádios de desenvolvimento ${ }^{(1)}$.

\begin{tabular}{|c|c|c|c|c|c|c|}
\hline \multirow{2}{*}{ Biótipo } & \multicolumn{2}{|c|}{ Duas folhas } & \multicolumn{2}{|c|}{ Quatro folhas } & \multicolumn{2}{|c|}{ Um ou dois afilhos } \\
\hline & Com glifosato & Sem glifosato & Com glifosato & Sem glifosato & Com glifosato & Sem glifosato \\
\hline & \multicolumn{6}{|c|}{ Controle aos 10 DAT } \\
\hline 12.1 & $99 * \mathrm{Aa}$ & $0 \mathrm{Aa}$ & $75 * \mathrm{Bb}$ & $0 \mathrm{Aa}$ & $45^{*} \mathrm{Ac}$ & $0 \mathrm{Aa}$ \\
\hline 12.3 & $100 * \mathrm{Aa}$ & $0 \mathrm{Aa}$ & $97 * \mathrm{Aa}$ & $0 \mathrm{Aa}$ & $40 * \mathrm{Ab}$ & 0Aa \\
\hline Suscetível & $100 * \mathrm{Aa}$ & $0 \mathrm{Aa}$ & $94 * \mathrm{Aa}$ & $0 \mathrm{Aa}$ & $44 * \mathrm{Ab}$ & $0 \mathrm{Aa}$ \\
\hline \multirow[t]{2}{*}{ CV (\%) } & \multicolumn{6}{|c|}{10,14} \\
\hline & \multicolumn{6}{|c|}{ Controle aos 20 DAT } \\
\hline 12.1 & $100 * \mathrm{Aa}$ & $0 \mathrm{Aa}$ & $83 * \mathrm{Bb}$ & OAa & $74 * \mathrm{Bc}$ & $0 \mathrm{Aa}$ \\
\hline 12.3 & $100 * \mathrm{Aa}$ & $0 \mathrm{Aa}$ & $92 * \mathrm{Ab}$ & $0 \mathrm{Aa}$ & $70 * \mathrm{Bc}$ & 0Aa \\
\hline Suscetível & $100 * \mathrm{Aa}$ & $0 \mathrm{Aa}$ & $93 * \mathrm{Ab}$ & $0 \mathrm{Aa}$ & $88 * \mathrm{Ab}$ & $0 \mathrm{Aa}$ \\
\hline \multirow[t]{2}{*}{$\mathrm{CV}(\%)$} & \multicolumn{6}{|c|}{8,75} \\
\hline & \multicolumn{6}{|c|}{ Controle aos 30 DAT } \\
\hline 12.1 & $100 * \mathrm{Aa}$ & $0 \mathrm{Aa}$ & $70 * \mathrm{Bc}$ & $0 \mathrm{Aa}$ & $80 * \mathrm{Bb}$ & $0 \mathrm{Aa}$ \\
\hline 12.3 & $100 * \mathrm{Aa}$ & $0 \mathrm{Aa}$ & $87 * \mathrm{Ab}$ & $0 \mathrm{Aa}$ & $74 * \mathrm{Cc}$ & $0 \mathrm{Aa}$ \\
\hline Suscetível & $100 * \mathrm{Aa}$ & $0 \mathrm{Aa}$ & $92 * \mathrm{Ab}$ & $0 \mathrm{Aa}$ & $93 * \mathrm{Ab}$ & $0 \mathrm{Aa}$ \\
\hline \multirow[t]{2}{*}{$\mathrm{CV}(\%)$} & \multicolumn{6}{|c|}{9,89} \\
\hline & \multicolumn{6}{|c|}{ Massa de matéria seca da parte aérea } \\
\hline 12.1 & $0,0082 * \mathrm{~A}$ & $0,2011 \mathrm{~A}$ & $0,0343 * \mathrm{~A}$ & $0,2105 \mathrm{AB}$ & $0,0924 * \mathrm{~B}$ & $0,2769 \mathrm{~A}$ \\
\hline 12.3 & $0,0056^{*} \mathrm{~A}$ & $0,2328 \mathrm{~A}$ & $0,0135 * \mathrm{~A}$ & $0,2253 \mathrm{~A}$ & $0,1995 * \mathrm{~A}$ & $0,2544 \mathrm{~A}$ \\
\hline Suscetível & $0,0047 * \mathrm{~A}$ & $0,2246 \mathrm{~A}$ & $0,0205 * \mathrm{~A}$ & $0,1618 \mathrm{~B}$ & $0,0879 * \mathrm{~B}$ & $0,2789 \mathrm{~A}$ \\
\hline
\end{tabular}

${ }^{(1)}$ Médias seguidas de letras iguais, maiúsculas nas colunas, na comparação de biótipos, e minúsculas nas linhas, na comparação de épocas de aplicação, não diferem pelo teste de Tukey, a 5\% de probabilidade. *Significativo pelo teste t, a 5\% de probabilidade, na comparação dos resultados da aplicação ou não de glifosato. DAT, dias após o tratamento. 
em $75 \%$ das lavouras amostradas, não é realizada a rotação de culturas, apenas a sucessão de culturas no cultivo de inverno (Figura 1). Nos 25\% dos casos em que foi observado o uso da rotação de culturas na área, os produtores utilizaram a cultura do milho como alternativa. Nesses casos, a área é manejada, no inverno, com trigo, e o milho é implantado entre dois anos consecutivos de soja, com uso predominante do herbicida nicosulfuron para o manejo das plantas daninhas. Nohatto (2010) constatou que o milho é a principal alternativa de cultura em rotação/sucessão com soja RR no RS (45\% dos casos), seguido por trigo, girassol e feijão.

Cabe destacar o risco de se utilizar a cultura do milho como única opção de rotação, visto que estão disponíveis, para comercialização, genótipos desta cultura com resistência ao herbicida glifosato, o que pode proporcionar rotação de culturas, mas não de mecanismo herbicida. No entanto, mesmo com o uso de culturas RR para rotação, há alternativas para manejo da área, como, por exemplo, o manejo na entressafra com outros herbicidas.

Os resultados dos questionários também evidenciaram que a maioria dos produtores realiza apenas manejo de inverno nestas áreas. Entre os produtores que somente utilizam a sucessão de culturas, os manejos de inverno predominantes foram pecuária (33\%), por meio da implantação de pastagem, e o plantio de plantas de cobertura $(25 \%)$ com o intuito de formar a palhada para a semeadura direta. A grande maioria dos produtores entrevistados utiliza aveia-branca (Avena sativa L.) associada a outra forma de cobertura do solo, como nabo-forrageiro (Raphanus sativus L.) e azevém (Lolium multiflorum Lam.). Outra parte utiliza o trigo (17\%) como alternativa para sucessão.

O manejo das áreas durante o inverno reduz a população de plantas daninhas, conforme observado para Conyza bonariensis (L.) Cronquist resistente ao glifosato, que teve sua população diminuída em $75 \%$, quando a área foi manejada no inverno com o trigo, e em $60 \%$, com a aveia-preta, em comparação à área mantida em pousio (Paula et al., 2011). Além disso, esses autores observaram redução de, aproximadamente, $67 \%$ na população da planta daninha ao utilizar o herbicida iodosulfurom-metílico na cultura do trigo. Dessa forma, ressalta-se a importância de se manejar a área no período da entressafra da cultura. $\mathrm{O}$ manejo adequado nesse período pode reduzir a emergência de plantas daninhas pela contínua ocupação do espaço e pelo próprio efeito supressor das culturas e da palha, além de possíveis efeitos favoráveis decorrentes da aplicação de herbicidas diferentes dos utilizados na safra principal.

Quanto ao uso de glifosato em áreas onde foram coletadas as plantas de capim pé-de-galinha com suspeita de resistência, $61 \%$ dos produtores realizam dessecação em pré-semeadura, além da aplicação do herbicida em pós-emergência da soja RR (Figura 2). Assim, em 92\% dos casos são realizadas duas aplicações de glifosato por cultivo da soja, divididas
A

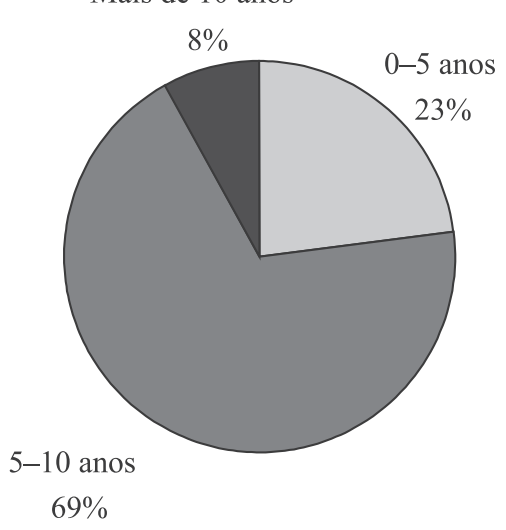

B

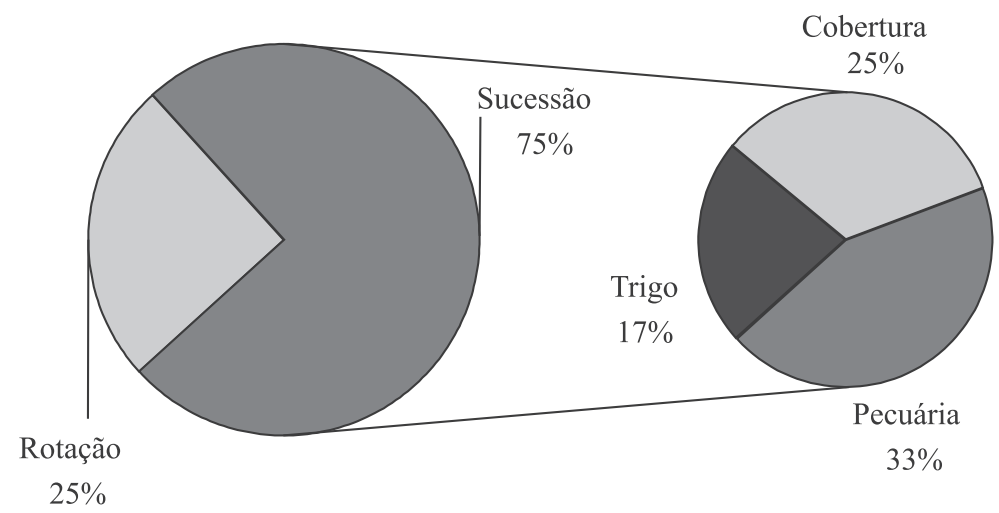

Figura 1. Tempo de cultivo contínuo (A) e métodos de manejo da área na entressafra da cultura da soja Roundup Ready (B), em lavouras com falhas de controle de Eleusine indica pelo herbicida glifosato, no Estado do Rio Grande do Sul. 
em manejo de dessecação e de pós-emergência, ou somente duas aplicações em pós-emergência.

Em cerca de $80 \%$ dos casos com suspeita de ocorrência de E. heterophylla resistente, em áreas de soja RR, no Rio Grande do Sul, o número de aplicações anuais de glifosato foi de três vezes ou mais (Nohatto, 2010). Beckie (2011) relata que a combinação de alta frequência de aplicação com o cultivo sequencial de culturas resistentes ao herbicida favorece a rápida seleção de plantas daninhas resistentes e a ocorrência de resistência antes do tempo previsto. Como consequência da seleção, as vantagens do controle das plantas daninhas na soja RR podem ser perdidas a curto ou a médio prazo, o que inviabilizaria, rapidamente, o uso dessa tecnologia (Nohatto, 2010).

A utilização de doses corretas do glifosato, na época e no estádio adequados das plantas daninhas (Givens et al., 2011), é considerada prática importante pelos produtores para reduzir a ocorrência de resistência a este herbicida. Constatou-se que, na maior parte das lavouras amostradas, a dose de glifosato utilizada, tanto para a dessecação pré-semeadura (67\%) (Figura 2 B) como para as aplicações em pós-emergência (54\%), encontra-se entre 720 e $1.080 \mathrm{~g} \mathrm{ha}^{-1}$ do e.a. Nohatto (2010) relata doses semelhantes do produto, em lavouras de soja RR com suspeita de ocorrência E. heterophylla resistente ao glifosato. Segundo Busi \& Powles (2009), doses de glifosato abaixo das recomendadas, entre 150 e $350 \mathrm{~g} \mathrm{ha}^{-1}$ do e.a., selecionaram população de Lolium rigidum Gaudin resistente, após três ciclos de seleção.

$\mathrm{O}$ uso de herbicidas com i.a. diferente do glifosato propiciou controles, em geral, acima de $84 \%$ aos 27
DAT (Tabela 2). O menor controle do biótipo 12.1 com o glifosato, aos 18 e 27 DAT, pode ser explicado pelo estádio avançado de crescimento que esse biótipo apresentava por ocasião da aplicação dos tratamentos. Os herbicidas cletodim, fluazifope-P-butílico (inibidores da acetil-CoA carboxilase, ACCase), clomazona e glufosinato de amônio foram eficientes para o controle dos biótipos de capim pé-de-galinha. Burke et al. (2005) também relataram controle eficiente desta espécie com os herbicidas cletodim e glufosinato de amônio, sendo que o primeiro foi eficiente em plantas de até seis afilhos. Entretanto, há também relatos de resistência de capim pé-de-galinha aos inibidores da ACCase (Vidal et al., 2006), o que aponta para o risco de resistência caso haja alta pressão de seleção. O glufosinato de amônio pode ser considerado uma alternativa interessante para uso em rotação de culturas, visto que há disponível, no mercado, genótipos de milho geneticamente modificado para resistência a este herbicida.

$\mathrm{O}$ uso de herbicidas com efeito residual é uma estratégia eficiente, indicada para o manejo de plantas daninhas resistentes ao glifosato em lavouras de soja RR, nos Estados Unidos (Owen et al., 2011). Contudo, é importante salientar que esses herbicidas proporcionam aumento da pressão de seleção, por permitirem o controle de diferentes fluxos de emergência de plantas daninhas. Dessa forma, recomenda-se que os produtores planejem as práticas de controle que envolvam a aplicação de herbicidas alternativos, para mitigar a evolução da resistência de capim pé-de-galinha ao glifosato.
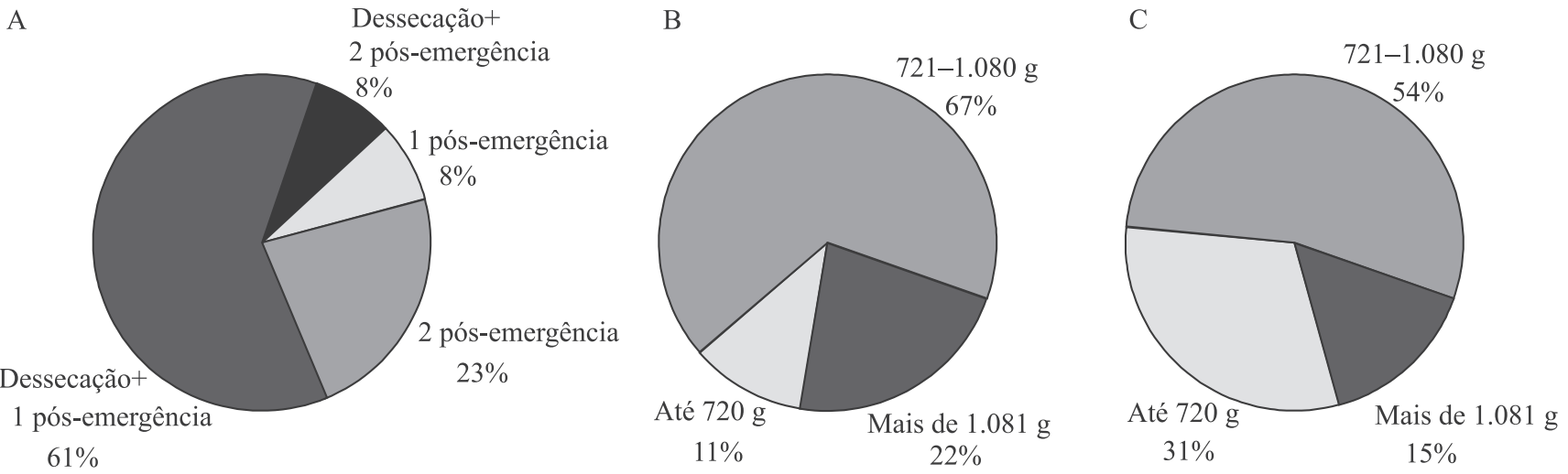

Figura 2. Número e época de aplicações de glifosato (A) e doses ( $\mathrm{g} \mathrm{ha}^{-1}$ do e.a.) utilizadas na dessecação (B) e em aplicação pós-emergência (C), em lavoura de soja Roundup Ready, com falhas de controle de Eleusine indica, no Estado do Rio Grande do Sul. 
Tabela 2. Controle (\% de plantas mortas), aos 9, 18 e 27 dias após a aplicação do tratamento (DAT), de biótipos (12.1, 12.3 e suscetível) de Eleusine indica oriundos de plantas escapes ao controle com glifosato, em resposta à aplicação de diferentes herbicidas ${ }^{(1)}$.

\begin{tabular}{lccc}
\hline Herbicida & Biótipo 12.1 & Biótipo 12.3 & Suscetível \\
\hline Cletodim & \multicolumn{3}{c}{$9 \mathrm{DAT}$} \\
Fluazifope-P-butílico & $94 \mathrm{Aa}$ & $74 \mathrm{Ba}$ & $70 \mathrm{Ba}$ \\
Clomazona & $92 \mathrm{Aa}$ & $86 \mathrm{ABa}$ & $76 \mathrm{Ba}$ \\
Glufosinato de amônio & $90 \mathrm{Aa}$ & $99 \mathrm{Aa}$ & $96 \mathrm{Aa}$ \\
Glifosato & $76 \mathrm{Aa}$ & $85 \mathrm{ABa}$ & $94 \mathrm{Aa}$ \\
\hline CV (\%) & \multicolumn{3}{c}{7,87} \\
\hline & $18 \mathrm{DAT}$ \\
Cletodim & $89 \mathrm{Aa}$ & $88 \mathrm{Aa}$ & $87 \mathrm{Aa}$ \\
Fluazifope-P-butílico & $99 \mathrm{Aa}$ & $98 \mathrm{Aa}$ & $93 \mathrm{Aa}$ \\
Clomazona & $85 \mathrm{Aa}$ & $88 \mathrm{Aa}$ & $86 \mathrm{Aa}$ \\
Glufosinato de amônio & $84 \mathrm{Aa}$ & $100 \mathrm{Aa}$ & $98 \mathrm{Aa}$ \\
Glifosato & $77 \mathrm{Ab}$ & $94 \mathrm{Aa}$ & $99 \mathrm{Aa}$ \\
\hline CV (\%) & \multicolumn{3}{c}{8,26} \\
\hline & $27 \mathrm{DAT}$ \\
Cletodim & $96 \mathrm{Aa}$ & $98 \mathrm{Aa}$ & $95 \mathrm{Aa}$ \\
Fluazifope-P-butílico & $100 \mathrm{Aa}$ & $100 \mathrm{Aa}$ & $95 \mathrm{Aa}$ \\
Clomazona & $90 \mathrm{ABa}$ & $94 \mathrm{Aa}$ & $84 \mathrm{Aa}$ \\
Glufosinato de amônio & $85 \mathrm{ABa}$ & $100 \mathrm{Aa}$ & $100 \mathrm{Aa}$ \\
Glifosato & $65 \mathrm{Bb}$ & $96 \mathrm{Aa}$ & $100 \mathrm{Aa}$ \\
\hline CV (\%) & & 9,77 & \\
\hline
\end{tabular}

${ }^{(1)}$ Médias seguidas de letras iguais, maiúsculas nas colunas e minúsculas nas linhas, não diferem pelo teste de Tukey, a $5 \%$ de probabilidade.

\section{Conclusões}

1. O controle de capim pé-de-galinha é superior quando as plantas recebem a aplicação do herbicida glifosato em estádio vegetativo de duas folhas.

2. O uso contínuo e em baixas doses do herbicida glifosato, a aplicação em estádios de desenvolvimento avançados das plantas daninhas (mais de um afilho) e a ausência de rotação de culturas são práticas associadas à seleção de biótipos resistentes de capim pé-de-galinha.

3. Os herbicidas cletodim, fluazifope-P-butílico, clomazona e glufosinato de amônio são alternativas eficientes ao herbicida glifosato, para o controle de capim pé-de-galinha.

\section{Referências}

BECKIE, H.J. Herbicide-resistant weed management: focus on glyphosate. Pest Management Science, v.67, p.1037-1048, 2011. DOI: $10.1002 /$ ps.2195.
BRASIL. Ministério da Agricultura, Pecuária e Abastecimento. Agrofit. Disponível em: <www.agricultura.gov.br>. Acesso em: 30 set. 2010.

BURKE, I.C.; ASKEW, S.D.; CORBETT, J.L.; WILCUT, J.W. Glufosinate antagonizes clethodim control of goosegrass (Eleusine indica). Weed Technology, v.19, p.664-668, 2005. DOI: 10.1614/ WT-04-214R1.1.

BUSI, R.; POWLES, S.B. Evolution of glyphosate resistance in a Lolium rigidum population by glyphosate selection at sublethal doses. Heredity, v.103, p.318-325, 2009. DOI: 10.1038/ hdy.2009.64.

CHRISTOFFOLETI, P.J.; LÓPEZ-OVEJERO, R. Principais aspectos da resistência de plantas daninhas ao herbicida glyphosate. Planta Daninha, v.21, p.507-515, 2003. DOI: 10.1590/ S0100-83582003000300020.

FRANS, R.; TALBERT, R.; MARX, D.; CROWLEY, H. Experimental design and techniques for measuring and analyzing plant responses to weed control practices. In: CAMPER, N.D. (Ed.). Research methods in weed science. 3.ed. Champaign: Southern Weed Science Society, 1986. p.29-46.

GAZZIERO, D.L.P.; CHRISTOFFOLETI, P.J.; VARGAS, L.; KRUSE, N.D.; GALLI, A.J.B.; TREZZI, M.M. Critérios para relatos oficiais estatísticos de biótipos de plantas daninhas resistentes a herbicidas. In: AGOSTINETTO, D.; VARGAS, L. (Ed.). Resistência de plantas daninhas a herbicidas no Brasil. Passo Fundo: Berthier, 2009. p.91-101.

GIVENS, W.A.; SHAW, D.R.; NEWMAN, M.E.; WELLER, S.C.; YOUNG, B.G.; WILSON, R.; OWEN, M.D.K.; JORDAN, D.L. Benchmark study on glyphosate-resistant cropping systems in the United States. Part 3: grower awareness, information sources, experiences and management practices regarding glyphosate-resistant weeds. Pest Management Science, v.67, p.758-770, 2011. DOI: 10.1002/ps.2178.

INSTITUTO BRASILEIRO DE GEOGRAFIA E ESTATÍSTICA. Produção agrícola municipal 2006. Disponível em: $<$ http://www. ibge.gov.br/home/estatistica/economia/pam/2006/default.shtm>. Acesso em: 25 abr. 2008.

JOHNSON, W.G.; GIBSON, K.D. Glyphosate-resistant weeds and resistance management strategies: an Indiana grower perspective. Weed Technology, v.20, p.768-772, 2006. DOI: 10.1614/ WT-05-122R1.1.

KISSMANN, K.G. Plantas infestantes e nocivas. 3.ed. São Paulo: BASF, 2007.

MOREIRA, M.S.; MELO, M.S.C.; CARVALHO, S.J.P.; NICOLAI, M.; CRHISTOFFOLETI, P.J. Herbicidas alternativos para controle de biótipos de Conyza bonariensis e C. canadensis resistentes ao glyphosate. Planta Daninha, v.28, p.167-175, 2010. DOI: $10.1590 / \mathrm{S} 0100-83582010000100020$.

NOHATTO, M.A. Resposta de Euphorbia heterophylla proveniente de lavouras de soja Roundup Ready do Rio Grande do Sul ao herbicida glyphosate. 2010. 76p. Dissertação (Mestrado) - Universidade Federal de Pelotas, Pelotas.

OWEN, M.D.K.; YOUNG, B.G.; SHAW, D.R.; WILSON, R.G.; JORDAN, D.L.; DIXON, P.M.; WELLER, S.C. Benchmark study 
on glyphosate-resistant crop systems in the United States. Part 2: perspectives. Pest Management Science, v.67, p.747-757, 2011. DOI: $10.1002 / \mathrm{ps} .2159$.

PAULA, J.M. de; VARGAS, L.; AGOSTINETTO, D.; NOHATTO, M.A. Manejo de Conyza bonariensis resistente ao herbicida glyphosate. Planta Daninha, v.29, p.217-227, 2011. DOI: 10.1590/ S0100-83582011000100024.

ROMAN, E.S.; VARGAS, L.; RIZZARDI, M.A.; MATTEI, R.W. Resistência de azevém (Lolium multiflorum) ao herbicida glyphosate. Planta Daninha, v.22, p.301-306, 2004. DOI: 10.1590/ S0100-83582004000200018.

SHANER, D.L. The impact of glyphosate-tolerant crops on the use of other herbicides and on resistance management. Pest Management Science, v.56, p.320-326, 2000. DOI: 10.1002/ (SICI)1526-4998(200004)56:4<320::AID-PS125>3.0.CO;2-B.

SILVA, A.A. da; FERREIRA, A.F.; FERREIRA, L.R. Herbicidas: classificação e mecanismos de ação. In: SILVA, A.A. da; SILVA, J.F. da. (Ed.). Tópicos em manejo de plantas daninhas. Viçosa: UFV, 2007. p.83-148.

VARGAS, L.; BIANCHI, M.A.; RIZZARDI, M.A.; AGOSTINETTO, D.; DAL MAGRO, T. Buva(Conyza bonariensis) resistente ao glyphosate na região Sul do Brasil. Planta Daninha, v.25, p.573-578, 2007. DOI: 10.1590/S0100-83582007000300017.
VARGAS, L.; NOHATTO, M.A.; AGOSTINETTO, D.; BIANCHI, M.A.; GONÇALVES, E.M.; TOLEDO, R.E. Resposta de biótipos de Euphorbia heterophylla a doses de glyphosate. Planta Daninha, v.29, p.1121-1128, 2011. DOI: 10.1590/S010083582011000500020 .

VIDAL, R.A.; PORTES, E.S.; LAMEGO, F.P.; TREZZI, M.M. Resistência de Eleusine indica aos inibidores de ACCase. Planta Daninha, v.24, p.163-171, 2006. DOI: 10.1590/ S0100-83582006000100021.

VILA-AIUB, M.M.; VIDAL, R.A.; BALBI, M.C.; GUNDEL, P.E.; TRUCCO, F.; GHERSA, C.M. Glyphosate-resistant weeds of South American cropping systems: an overview. Pest Management Science, v.64, p.366-371, 2008. DOI: 10.1002/ps.1488.

ZAWIERUCHA, J.E.; PENNER, D. The relationship of goosegrass (Eleusine indica) stage of growth to quinclorac tolerance. Weed Technology, v.15, p.216-219, 2001. DOI: 10.1614/0890-037X(20 01)015[0216:TROGEI]2.0.CO;2.

ZELAYA, I.A.; OWEN, M.D.K.; VANGESSEL, M.J. Inheritance of evolved glyphosate resistance in Conyza canadensis (L.) Cronq. Theoretical and Applied Genetics, v.110, p.58-70, 2004. DOI: 10.1007/s00122-004-1804-8.

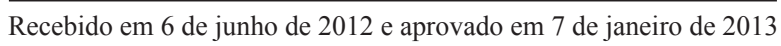

